\title{
Reasonableness of phase change materials use for air conditioning - a short review
}

\author{
Marta Kuta $^{1 *}$, Dominika Matuszewska ${ }^{1}$ and Tadeusz M. Wójcik ${ }^{1}$ \\ ${ }^{1}$ AGH University of Science and Technology, Faculty of Energy and Fuels, Department of Thermal \\ and Fluid Flow Machines, al. A. Mickiewicza 30, 30-059 Krakow
}

\begin{abstract}
PCM-based systems for cooling of building spaces are a developing area with great potential. Especially since cooling systems are becoming more popular resulting in increased demand for energy. The aim of this work is to analyse how application of phase change materials can support and improve cooling efficiency of air conditioning. Authors discuss and compare different types of PCM-based solutions.
\end{abstract}

\section{Introduction}

It can be observed over last few years that with an improvement of quality of life, usage of air conditioning becomes more frequent [1]. The consequence of this situation is the increase of the demand for energy not only for heating, but also for cooling, what causes general increase of energy consumption for thermal stabilization of buildings. It is important to improve existing and design new systems for controlling temperature, ventilation and humidity of buildings. Especially if we take into consideration how growing use of air conditioning influences the energy consumption. One of the possibilities for improving cooling efficiency of air conditioning is use of phase change materials (PCMs). It can be one of efficient method for improving the process as well as reducing the size of the system. Phase change materials are able to absorb, store and release large amount of heat. It is promising storage medium for a large number of applications such as waste-heat recovery, cooling and heating of buildings or heat pump-systems [2]. It is also considered for air conditioning systems. Phase change materials can be design to change the phase at the suitable temperature range, phase change temperature can also be designed for air conditioning requirements [3].

\section{PCM for cooling applications in buildings (including air conditioning)}

Phase change materials are substances which the most important attribute is the ability to absorb, store and release the heat under certain circumstances. General principle of operation is the same, but properties (phase change transition temperature, latent heat of fusion, specific heat, thermal conductivity, aspirations for gas generation and changes in

\footnotetext{
* Corresponding author: marta.kuta@agh.edu.pl
} 
volume during the transition, life span, tendency to corrosion, flammability or explosiveness, subcooling, recyclability, environmental friendliness, availability or cost) are individual for every material. Figure 1 presents the schematic work of phase change materials on the example of solid-liquid PCMs. For this kind of transition it can be observed that when the ambient temperature rises, the temperature of PCM also rises. When temperature reaches the level of phase transition PCM starts to melt and at the same time absorb heat without changes in PCM temperature. When the temperature decreases the opposite process occurs. PCM releases the heat and returns to original solid state.

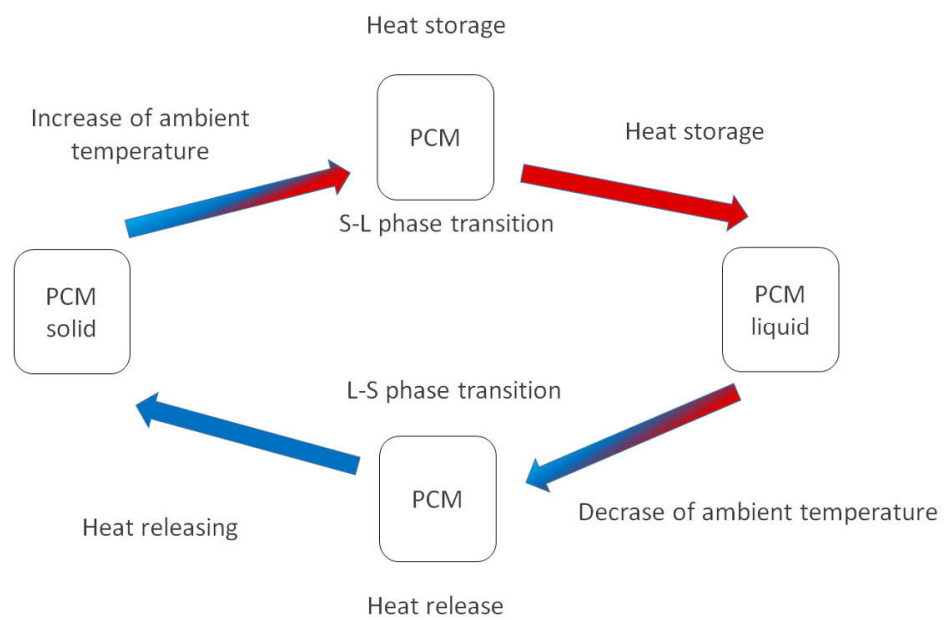

Fig. 1. The scheme of transition for solid - liquid phase change materials

Phase change materials can be used to store the thermal energy or to stabilise the temperature in the specific range. This is the reason why they have a big potential for building applications. In order to maximize the impact of PCM use, detailed analysis of the properties in order to select the most advantageous solution is necessary. The most important properties have been included in table 1 . They refer to every type of PCM: organic (paraffin, non-paraffin), inorganic (salt hydrate, metallic) and eutectics (organicorganic, inorganic-inorganic, inorganic-organic)

Table 1. Important properties and requirements of phase change materials[4]

\begin{tabular}{|c|c|c|c|}
\hline \multicolumn{4}{|c|}{ Important properties and requirements of phase change materials } \\
\hline Thermo - physical & Kinetic & Chemical & $\begin{array}{c}\text { Another (economical, } \\
\text { environmental) }\end{array}$ \\
\hline $\begin{array}{l}\text { - suitable temperature of } \\
\text { phase transition, } \\
\text { - high latent heat of } \\
\text { transition, } \\
\text { - high specific heat, } \\
\text { - high thermal conductivity, } \\
\text { - high density, } \\
\text { - small or no volume } \\
\text { change, } \\
\text { - minimal gas generation } \\
\text { during the transition }\end{array}$ & $\begin{array}{l}\text { - minimal } \\
\text { subcooling, } \\
\text { - high rate of } \\
\text { crystallization }\end{array}$ & $\begin{array}{l}\text { - no degradation and } \\
\text { stability of properties } \\
\text { after many cycles, } \\
\text { - complete reversibility } \\
\text { - non-corrosive } \\
\text { - compatibility with the } \\
\text { system/construction, } \\
\text { - non-flammable, } \\
\text { - non-explosive, } \\
\text { - easy to recycle }\end{array}$ & $\begin{array}{l}\text { - cost-effective, } \\
\text { - environment } \\
\text { friendly, } \\
\text { - available }\end{array}$ \\
\hline
\end{tabular}


Number of phase change materials suitable for cooling applications in buildings are commercially available and numbers of new PCMs are investigated. Some of them have been selected and included in table 2 .

Table 2. Selected phase change materials suitable for cooling building applications

\begin{tabular}{|c|c|c|c|}
\hline Phase change material & $\begin{array}{c}\text { Melting } \\
\text { point, }{ }^{\circ} \mathbf{C}\end{array}$ & $\begin{array}{c}\text { Latent heat of } \\
\text { fusion, } \mathbf{k J} / \mathbf{k g}\end{array}$ & Reference \\
\hline Emerest 2325 & $17-21$ & $138-140$ & {$[5]$} \\
\hline Glycerin & 17.9 & 198.7 & {$[4]$} \\
\hline Hexadecane $\mathrm{CH}_{3}-\left(\mathrm{CH}_{2}\right)_{14}-\mathrm{CH}_{3}$ & 18 & 236 & {$[6]$} \\
\hline Paraffin $\mathrm{C} 16-\mathrm{C} 18$ & 19 & 152 & {$[7]$} \\
\hline $\mathrm{Na}_{2} \mathrm{SO}_{4} \cdot 10 \mathrm{H}_{2} \mathrm{O}$ & 21 & 198 & {$[8]$} \\
\hline Heptadecane $\mathrm{CH}_{3}-\left(\mathrm{CH}_{2}\right)_{15}-\mathrm{CH}_{3}$ & 22 & 214 & {$[6]$} \\
\hline $\mathrm{RT} 25 \mathrm{Paraffin}$ & 24 & 164 & {$[9]$} \\
\hline $\mathrm{Mn}\left(\mathrm{NO}_{3}\right)_{2} \cdot 6 \mathrm{H}_{2} \mathrm{O}$ & 25.8 & 125.9 & {$[10]$} \\
\hline Vinyl stearate & 27 & 122 & {$[10]$} \\
\hline Octadecane $\mathrm{CH}_{3}-\left(\mathrm{CH}_{2}\right)_{16}-\mathrm{CH}_{3}$ & 28 & 244 & {$[6]$} \\
\hline
\end{tabular}

Phase change materials from table 2 are only examples. There is wide range of phase change materials with different properties. The most important stage with PCMs applications is to choose material characterised by adequate properties for an application.

\section{PCM based systems}

Number of researchers conducted their reserch in the area of PCM based building thermal stabilisation, including air conditioning. Selected examples are shown and discussed in this paragraph.

Rahdar et al. [11] analyzed vapor compression air conditioning system via two strategies of hybrid systems: ice thermal energy storage system and PCM tank. Schematic configuration of two thermal storage systems are shown in figure 2. Authors analysed systems in order to check and compare capabilities of shifting the load from on-peak to offpeak mode from exergetic, economic and environmental point of views.
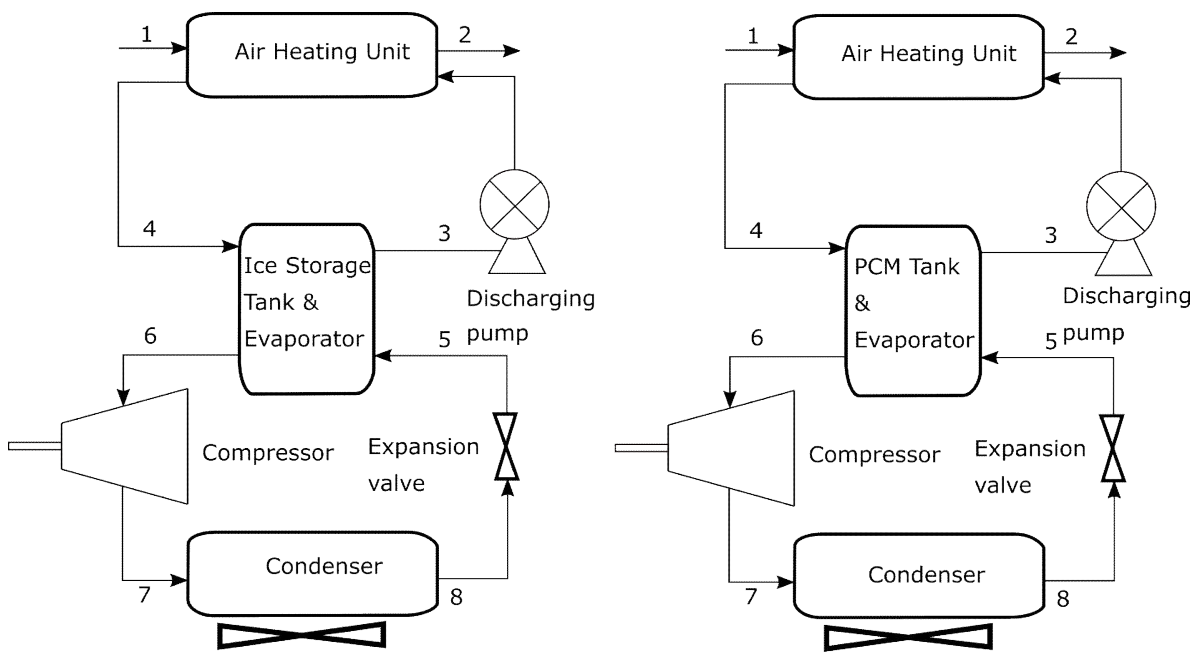

Fig. 2. Schematic configuration of two thermal storage systems[11] 
The summary of results shows that :

- power consumption in comparison to conventional system is $4.59 \%$ lower for ice system and $7.58 \%$ lower for PCM system

- $\mathrm{CO}_{2}$ emission production for ice system in comparison to conventional system is $17.8 \%$ lower for ice system and 27.2\% lower for PCM system

- calculated pay-back period amounts : 3.16 years for ice system and 5.56 years for PCM system.

Navidbakhsh et al. [12] analysed in their work energy, exergy, economic, and environmental aspects of the ice thermal energy storage system incorporating a phase change material module for air conditioning applications. Schematic diagram of the modeled ice thermal energy storage system incorporating PCM as the partial cold storage is presents in the figure 3. Authors compared system containing PCM module with the original ice system and with conventional air-conditioning system.

The summary of results shows that :

- power consumption for PCM system in comparison to ice system and conventional system was respectively $6.7 \%$ and $17.1 \%$ lower

- $\mathrm{CO}_{2}$ emission production for PCM system in comparison to ice system and conventional system decreased respectively 7.2 and $17.5 \%$

- calculated pay-back period amount : 3.97 years for PCM system and 3.39 years for ice system

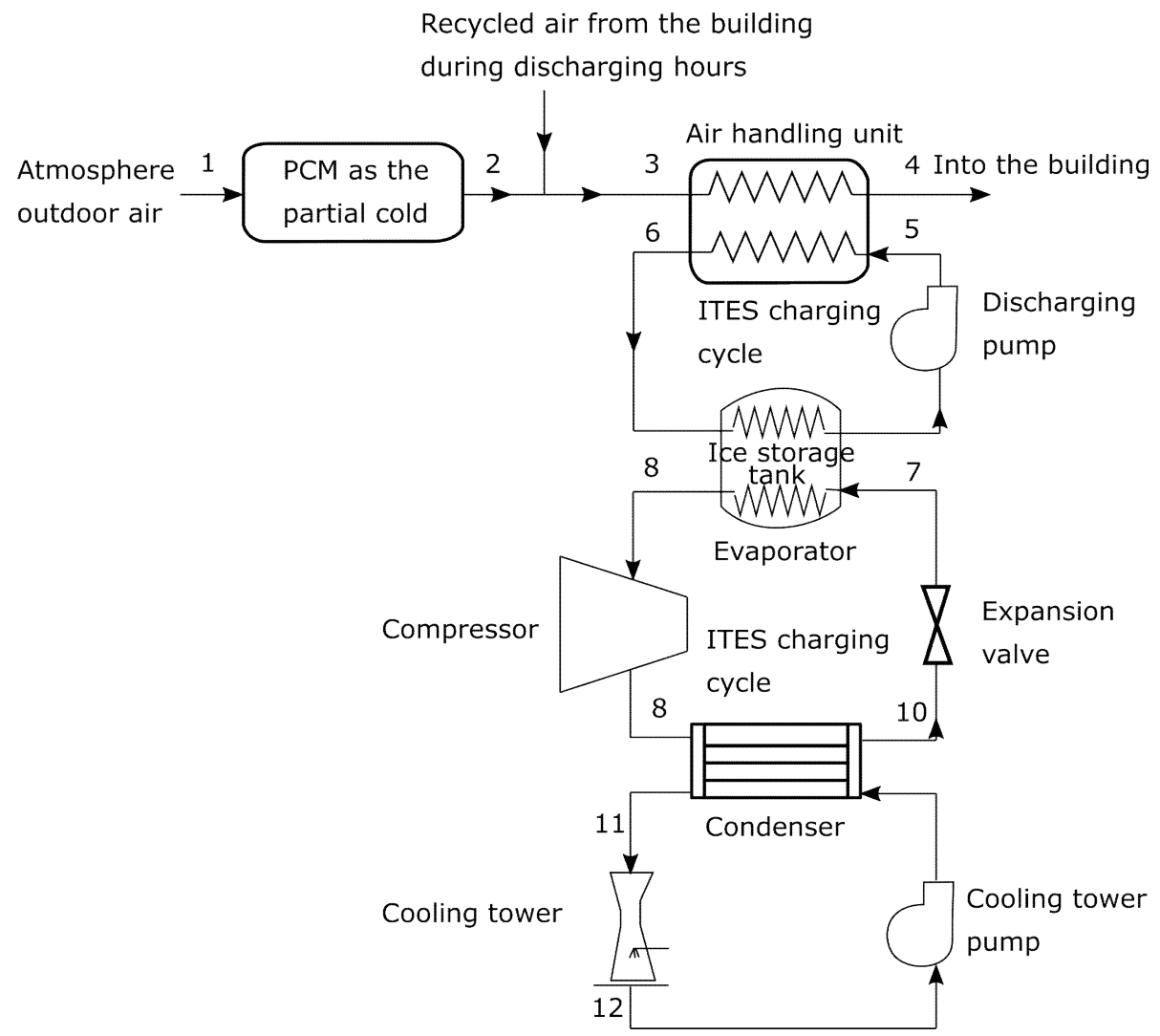

Fig. 3. Schematic diagram of the modeled ice thermal energy storage system incorporating PCM as the partial cold storage [12] 
Mostaffa et al. [13] present air conditioning system in the form of combination of a latent heat thermal storage unit and a refrigeration system. Figure 4 shows the schematic of the system.

Authors analyse three cases with different size ( 1 - length, d- thickness) of PCM slabs and different type of PCM. Description of all analysed by Author cases has been presened in table 3 .

Table 3. Description of parameters of PCM slab for three analysed by Authors cases[13]

\begin{tabular}{|l|l|l|l|}
\hline Case no. & Length, 1 & Thickness, d & PCM \\
\hline case 1 & $1.8 \mathrm{~m}$ & $15 \mathrm{~mm}$ & RT27 \\
\hline case 2 & $1.7 \mathrm{~m}$ & $10 \mathrm{~mm}$ & S27 \\
\hline case 3 & $1.4 \mathrm{~m}$ & $15 \mathrm{~mm}$ & SP25 \\
\hline
\end{tabular}

The analysis is conducted from exergoeconomic and environmental points of view. The analysis resulted with conclusions that considering: highest cooling load of $11.8 \mathrm{~kW}$, highest overall product exergy rate of $0.084 \mathrm{~kW}$, lowest investment cost rate of $0.026 \mathrm{M} \$$ and lowest amount of $\mathrm{CO}_{2}$ emission respectively: case 3 has the highest coefficient of performance (COP) of 3.434 , case 1 has the highest exergy efficiency of $2.93 \%$, case 2 has the lowest total cost rate of $4094 \$$ year.

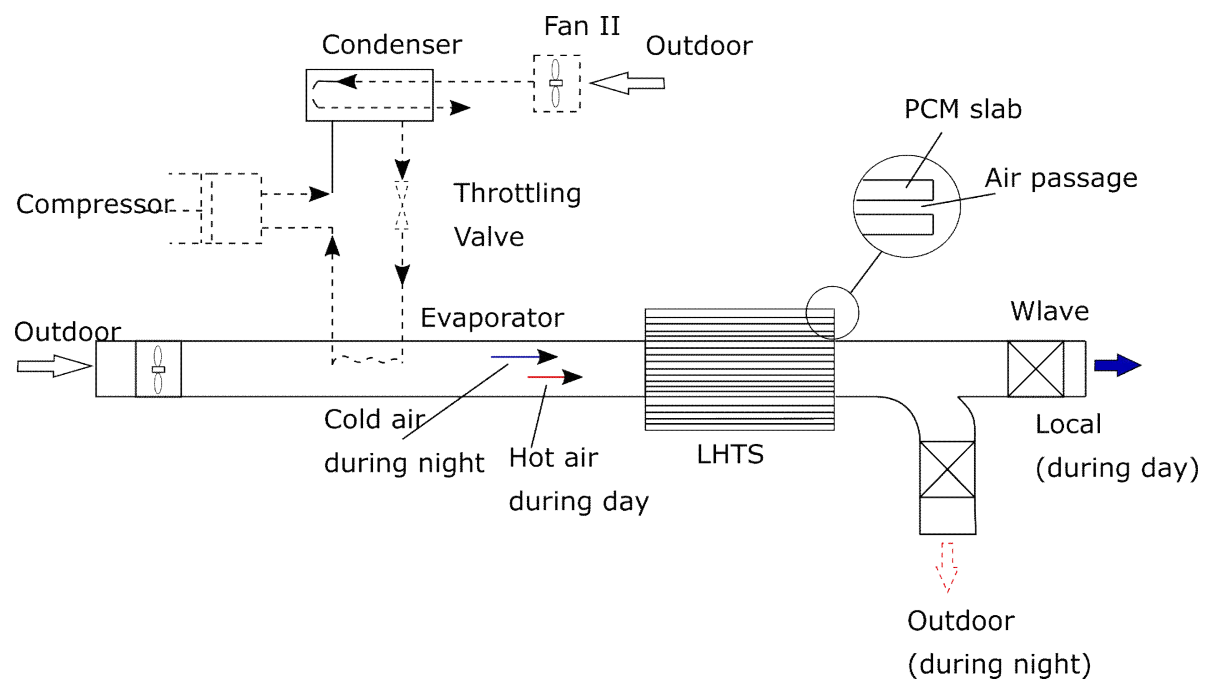

Fig. 4. Schematic of the air cooling system incorporating a latent heat thermal storage unit[13]

Zhao and Tank [14] present in their work possibility of integration of shell-and-tube based phase change material (PCM) thermal storage system with conventional air-conditioner. The proposed system use water (for charging loop) and air (for discharging loop) as a media for the heat transfer fluid. Schematic diagram of the air-conditioner integrated with PCM thermal storage is shown in the figure 5. 


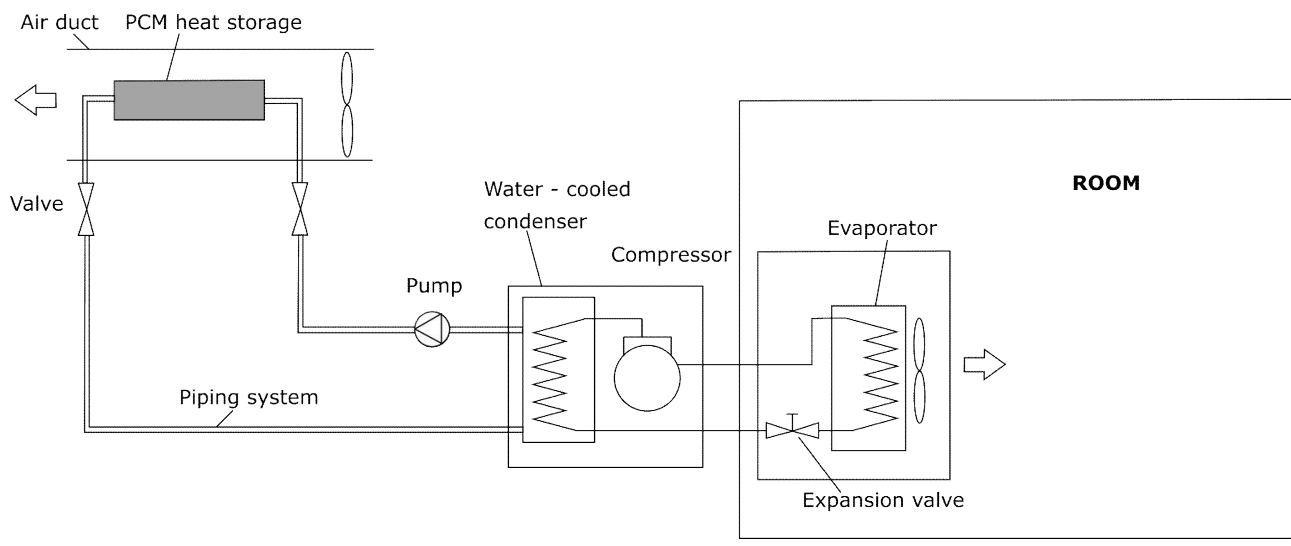

Fig. 5. Conceived schematic diagram of the air-conditioner integrated with PCM thermal storage[14]

Authors developed a numerical model for the PCM thermal storage unit and evaluated the influence on PCM TES system performance of heat transfer fluid inlet temperature, mass flow rate and conductive fin height. Authors give suggestions related to optimal parameters of both - the system and the system operation. They observed that charging time of the system depend on inlet temperature, mass flow rate and fin height: higher parameters schorter charging time. They also concluded that PCM based thermal energy storage system proposed in this work is easy to scale-up and is characterised by effectiveness higher than 0.5 .

Chaiyat[15] presents a concept of using phase change material for improving cooling efficiency of an airconditioner. They test modified air-conditioning system. Modification consists of addition of PCM ball pack bed. Research is conducted for Thailand climate. Experiment results are compared and verified with the mathematical model giving high consistency. Details of the testing room schematic are shown in figure 6 and some additional information are presented in table 4.

Author concluded that results show potential for using the packed ball bed of PCM (RT-20) to reduce energy consumption of the system under discussed circumstances and observes advantages:

- power consumption in comparison to conventional system is $9 \%(3.94 \mathrm{~kW} \mathrm{h/d})$ lower

- calculated pay-back period amounts: 3.16 years

Author selected for the purpose of the experiment phase change material manufactured by Rubitherm: RT-20, which is characterised by melting temperature: $22{ }^{\circ} \mathrm{C}$, freezing temperature: $20^{\circ} \mathrm{C}$ and heat of fusion: $160-180 \mathrm{~kJ} / \mathrm{kg}$. PCM ball was made from celluloid, diameter $4 \mathrm{~cm}$. PCM bed is filled with balls at arroud $70 \%$ volume.

Table 4. Charging and discharging performances of the PCM bed depends on its thickness[15]

\begin{tabular}{|l|l|l|l|}
\hline Thickness of the PCM bed, cm & 40 & 30 & 20 \\
\hline Number of PCM ball & 1100 & 933 & 619 \\
\hline Volume of PCM, liter & 57.60 & 48.85 & 32.41 \\
\hline Charging time, minute & 110 & 100 & 70 \\
\hline Discharging time, minute & 180 & 140 & 80 \\
\hline
\end{tabular}




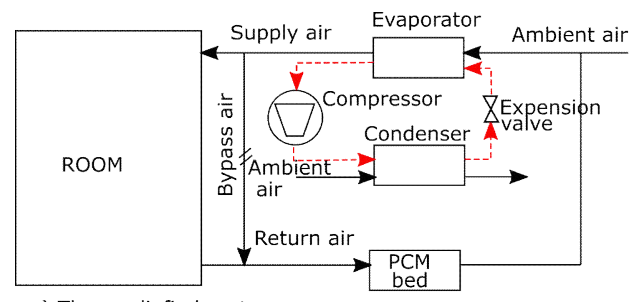

a) The modiefied system

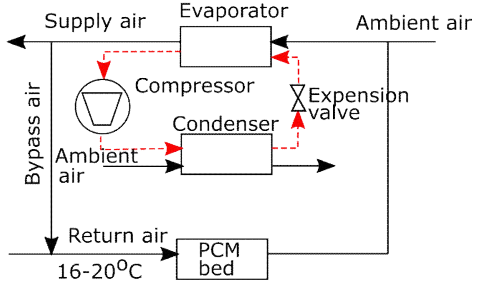

b) Charging operation

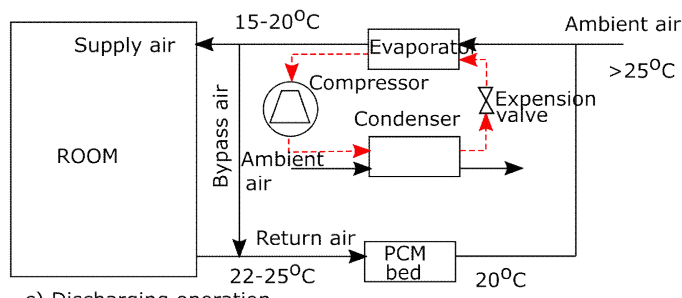

c) Discharging operation

Fig. 6. Schematic of the testing room[15]

\section{Summary}

Current researches and achievements in the field of building thermal stabilisation supported by the use of phase change materials show that there is a great potential, but also number of difficulties which have to be faced in the further works.

Wide range of different phase change materials are available on the market. They are group into three main groups (organic-organic, inorganic-inorganic, inorganic-organic) and it can be observed that the biggest attention is around organic PCMs, especially paraffins. Despite many advantages, there is also one main disadvantages for the paraffin use: low thermal conductivity. Many researches are conducted to reduce this problem. It is important to correctly choose the phase change material and construction of the thermal energy storage system in order to effective use of the system.

Phase change materials enable short and long therm thermal energy storage. For cooling building applications they are especialy useful fo the electrical energy peak load shifting. Proper use of phase change materials for air conditioning gives possibility of reducing the power consumption and $\mathrm{CO}_{2}$ emission.

Acknowledgement This work was supported by AGH - University of Science and Technology (Project 11.11.210.216).

\section{References}

1. L. W. Davisa and P. J. Gertlera, Proceedings of the National Academy of Science of the United States of America 112 (2015)

2. A. Sharma, V.V. Tyagi, C.R. Chen, D. Buddhi, Renewable and Sustainable Energy Reviews 13 (2009) 318-345

3. G. Li, Y. Hwang, R. Radermacher, International journal of refrigeration 35 (2012) 2053-2077

4. A. Sharma, V.V Tyagi, C.R. Chen, D. Buddhi, Renewable and Sustainable Energy Reviews 13, (2009) 318-345 
5. S. Scalat, D. Banu, D. Hawes, J. Paris, F. Haghighata, D. Feldman, Solar Energy Materials and Solar Cells 44 (1996) 49-61

6. M. Koschenz, B. Lehmann, Energy and Buildings 36 (2004) 567-578

7. B. Zalba, J.M. Marin, L.F. Cabeza, et al., International Journal of Refrigeration 27 (8) (2004) 839-849

8. J. Turnpenny, D. Etheridge, D. Reay, Applied Thermal Engineering 20 (2000) 10191037

9. J. Marin, B. Zalba, F. Cabeza, H. Mehling, International Journal of Refrigeration, 27 (2004), 839-849

10. P. Tatsidjodoung, N. Le Pierrès, L. Luo, Renew Sustain Energy Rev, 18 (2013), pp. 327-349

11. M. H. Rahdar, A. Emamzadeh , A.Ataei, Applied Thermal Engineering 96 (2016) 391399

12. M. Navidbakhsh, A. Shirazi, S. Sanaye, Applied Thermal Engineering 58 (2013) 30-41

13. A.H. Mosaffa, L. Garousi Farshi, Applied Energy 162 (2016) 515-526

14. D. Zhao, G. Tan, Applied Energy 138 (2015) 381-392

15. N. Chaiyat, Energy Conversion and Management 94 (2015) 150-158 